Gastric cancer (GC) is one of the most common malignant cancers worldwide. Intraperitoneal dissemination is the typical mechanism of the formation of metastases in GC. The diagnosis of the presence of intraperitoneal free cancer cells (IFCCs) is treated equally to the $M$ (metastasis) category according to the $8^{\text {th }}$ edition of the TNM classification by the American Joint Committee on Cancer. IFCCs are cells which have detached from the primary tumour through exfoliation into the peritoneal cavity. The source of IFCCs may be iatrogenic due to improper surgical technique during resection of the tumour and may lead to intraperitoneal dissemination. Cytological examination of peritoneal lavage is considered as a gold standard in the confirmation of the presence of IFCCs; however, its sensitivity is very low. In order to increase the sensitivity and reliability of the examination, molecular biology techniques should be applied. In the case of detection of the presence of IFCCs in patients with GC, the patient should be qualified for chemotherapy, or possibly the use of hyperthermic intraperitoneal chemotherapy should be considered.

Key words: free cancer cells, peritoneal cytology, gastric cancer, intraperitoneal cancer cells.

Contemp Oncol (Pozn) 2020; 24 (1): 67-74 DOI: https://doi.org/10.5114/wo.2020.94724

\section{Free cancer cells in gastric cancer - methods of detection, clinical and prognostic importance (meta-analysis)}

Magdalena M. Kołomańska, Stanisław Głuszek

Department of Surgery and Surgical Nursing with Laboratory of Genetics and Scientific Research, Collegium Medicum, Jan Kochanowski University, Kielce

General, Oncological and Endocrinological Surgery Clinic, Provincial Integrated Hospital in Kielce, Poland

\section{Introduction}

Gastric cancer (GC) is one of the most common malignant cancers worldwide - it occupies the fourth position according to incidence and the second according to mortality $[1,2]$. Within the last decades a decrease has been observed in the incidence of GC, which is due to higher standards of hygiene, better food preservation, high consumption of fresh fruits and vegetables, as well as eradication of Helicobacter pylori [1]. The majority of cases of GC are closely associated with environmental factors, such as tobacco smoking, alcohol abuse, infection with Helicobacter pylori, or Epstein-Barr virus [1]. Unmodifiable risk factors of GC are family history of GC, advanced age, male gender, low socioeconomic status and history of partial gastrectomy [1]. The prognosis in patients with GC is unfavourable, because of late detection. In the European countries 5-year survival rates range from 10 to $30 \%$, whereas these rates are relatively high in Japan - approximately $90 \%$. This is probably related to an early endoscopic diagnosis and resection of the tumour at its initial stage [1]. Surgical treatment is the main method of management of patients with locally advanced GC. The selection of the type of surgical procedure depends on the clinical stage (CTNM), degree of differentiation and location of the tumour. The 5-year survival of patients with GC remains an important clinical problem which requires further research in order to seek new treatment methods, especially neoadjuvant therapy [3].

Intraperitoneal dissemination is the typical mechanism of formation of metastases in GC [4]. Intraperitoneal recurrence is observed in 32-54\% of patients [5]. According to the 8th edition of the TNM classification for GC by the American Joint Committee of Cancer (AJCC), the detection of cancer cells in cytological preparations from puncture of the peritoneal cavity (in the case of ascites) categorizes this characteristic as M1 [6]. In the $13^{\text {th }}$ edition of the Japanese Classification of Gastric Carcinoma, the presence of free intraperitoneal cancer cells in the peritoneal cavity is classified as stage IV disease [7].

The stages of development of intraperitoneal dissemination are demonstrated by Paget's 'seed and soil' theory. Initially, cancer cells disconnect from the primary tumour and migrate to the peritoneum, where they attach to the mesothelial cells. The subsequent stage is their invasion through the basement membrane into the subperitoneal tissue and proliferation with angiogenesis [4].

Intraperitoneal free cancer cells (IFCCS) are cells which have detached from the primary tumour through exfoliation from its surface into the peritoneal cavity [7]. This process is caused, among other things, by a decrease in expression of adhesion proteins in GC cells [4]. The majority of IFCCs, after binding to the peritoneum, die due to poor nutrition and lack of vascularization. However, due to the CD44 adhesive particles on their surface, changes occur in the cytoskeleton of the cell and 
its migration into the subperitoneal space. Cancer cells strong ly bind to the exposed basement membrane of the peritoneal epithelium. Subsequently, they secrete proteinases degrading the peritoneal-blood barrier and penetrate deeper into the subperitoneal tissue. A further stage of invasion is the formation of new blood vessels which nourish the newly established intraperitoneal metastasis. The privileged sites, where intraperitoneal metastases are formed earlier, are the peritoneal lymphatic orifices. The IFCCs migrate through the lymphatic orifices into the lymphatic subperitoneal space and there they proliferate. There are many lymphatic orifices on the surface of the greater omentum, epiploic appendices of the colon, the lower surface of the diaphragm, falciform ligament of the liver, the pouch of Douglas, and the mesentery of the small intestine. At these sites, intraperitoneal metastases are more frequently observed. For comparison, on the parietal peritoneum or visceral peritoneum of the small intestine, liver and spleen, the number of lymphatic peritoneal orifices is smaller, and at these sites metastases into the peritoneum are observed as late as in advanced stages of intraperitoneal dissemination [7].

The source of IFCCs may also be iatrogenic - an improper surgical technique during the resection of the tumour may lead to dissemination of the IFCCS in the peritoneal cavity. Cancer cells are released from the cut lymphatic vessels, dissected tissue from the margin of cancer resection, as well as blood from the tumour which got into the surgical site [7]. This phenomenon has been confirmed by many studies using peritoneal lavage cytology prior to and after gastrectomy $[4,8]$.

The prognostic importance of IFCCS in GC remains unclear [9]. The objective of the study is to analyse the mechanism of formation, methods of detection, and clinical and prognostic importance of IFCCs in GC.

\section{Material and methods}

Scientific reports were searched for in the PubMed database. The following key words were entered: free cancer cells, gastric cancer, peritoneal lavage gastric cancer,

3106 scientific reports

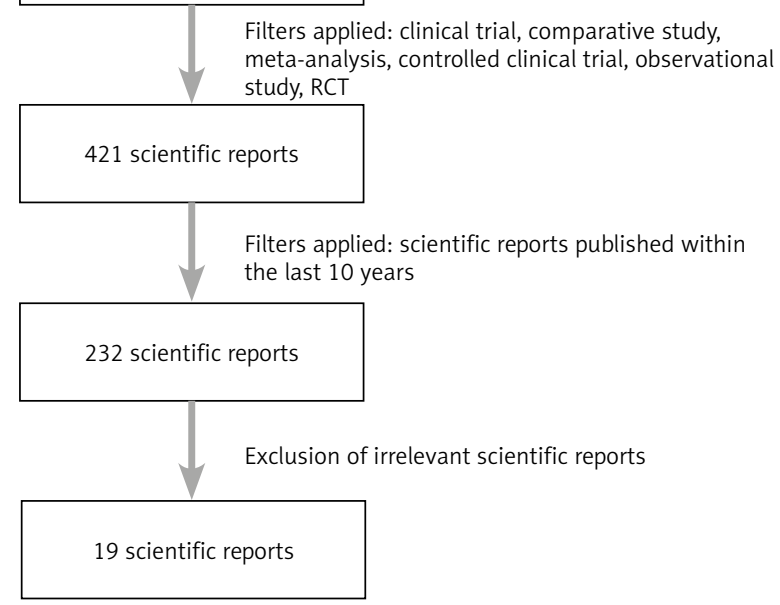

Fig. 1. Algorithm presenting the method of selecting scientific publications for this review peritoneal cytology gastric cancer, intraperitoneal cancer cells gastric cancer, obtaining a total of 3,106 results. After the use of the filters clinical trial, comparative study, meta-analysis, controlled clinical trial, observational study, RCT, 421 results were obtained. Subsequently, the filter was applied considering reports published within the last 10 years, obtaining 232 results. These results were subjected to analysis of their relevance to the subject of the study. As a result of the analysis, 19 scientific reports were included in the review. The data from the algorithm presented below (Fig. 1) were presented in the form of tables (Tables 1 and 2) and a meta-analysis (Fig. 2).

\section{Results}

In cytological examination of peritoneal lavage, in patients with GC, free cancer cells are detected with the frequency $6.25-54.4 \%$. Various factors contribute to the result of cytological examination, including the depth of tumour infiltration, the degree of its differentiation, use of chemotherapy, surgical procedures or lymphadenectomy $[3,5,11,15,20,24]$.

Table 1 presents the results of the analysed studies.

Details on meta-analytical method:

- random effects model,

- inverse variance method,

- DerSimonian-Laird estimator for tau²,

- Clopper-Pearson confidence interval for individual studies. Cytological examination of peritoneal lavage is considered as a gold standard in confirmation of the presence of free cancer cells in the peritoneal cavity, but its sensitivity is very low. The final meta-analysis result of the frequency of detection of IFCCS in GC using cytology as a diagnostic method indicates that the percentage of positive results is 18\% (95\% Cl: 14-24\%).

\section{Discussion}

Cytological examination applied independently for the detection of free cancer cells is characterized by relatively low sensitivity $[9,10,12,18]$. In order to increase the sensitivity of detection of free cancer cells it is necessary to apply the techniques of molecular biology. Fujiwara et al. [15] conducted a study comparing the effectiveness of detection of IFCCs using classical cytology and RT-PCR. The study included 137 patients. The material for research was obtained by applying peritoneal lavage using $100 \mathrm{ml}$ of saline. After gentle stirring, $50 \mathrm{ml}$ of the lavage fluid was collected from the peritoneal cavity. A half of the sample was designed for cytological examination, and the other half for RT-PCR assay. A positive result of cytology was observed in $20 \%$ of patients, whereas a positive result of the RT-PCR carcinoembryonic antigen mRNA was observed in $54 \%$ of patients. In addition, a poorer prognosis was noted in the form of shorter survival of patients with a positive result of RT-PCR assay. The researchers considered a positive result of RT-PCR as an independent prognostic factor. RT-PCR assay increases the sensitivity of detection of IFCCS of patients with GC [15]. Presence of IFCCS is classified as metastatic disease (M1) in TNM classification and it is associated with poorer prognosis of patients [6]. According to the multivariate analysis, 
Table 1. Compilation of scientific reports

\begin{tabular}{|c|c|c|c|c|c|c|c|}
\hline No. & First author & $\begin{array}{c}\text { Year of } \\
\text { publication }\end{array}$ & $\begin{array}{l}\text { No. of } \\
\text { patients }\end{array}$ & $\begin{array}{l}\text { Diagnostic } \\
\text { method }\end{array}$ & Treatment applied & $\begin{array}{c}\text { Positive result } \\
n(\%)\end{array}$ & Survival \\
\hline 1 & Kuramato [10] & 2009 & 1522 & Cytology & Lack & $88(5.8)$ & $\begin{array}{l}\text { 5-year survival: } \\
\text { surgical treatment: } 4.6 \% \\
\text { surgical treatment + } \\
\text { intraperitoneal chemotherapy + } \\
\text { peritoneal lavage: } 43.8 \%\end{array}$ \\
\hline \multirow[t]{2}{*}{2} & \multirow[t]{2}{*}{ Hao [11] } & \multirow[t]{2}{*}{2010} & 83 & \multirow[t]{2}{*}{$\begin{array}{l}\text { Cytology + } \\
\text { RT-PCR }\end{array}$} & $\begin{array}{l}\text { Laparoscopic } \\
\text { gastrectomy }\end{array}$ & $33(39.2)$ & \multirow{2}{*}{$\begin{array}{l}\text { Median survival: } \\
\text { presence of IFCCs: } 20 \text { months } \\
\text { lack of IFCCs: } 31 \text { months }\end{array}$} \\
\hline & & & 81 & & Classical gastrectomy & $36(44.3)$ & \\
\hline 3 & La Torre [12] & 2010 & 64 & Cytology & Lack & $7(11)$ & $\begin{array}{l}\text { Median: } 32 \text { months } \\
\text { 5-year: } 28 \%\end{array}$ \\
\hline 4 & Lorenzen [13] & 2010 & 61 & Cytology & Before neo-СTH & $19(31)$ & $\begin{array}{l}\text { Median survival: } 9.2 \text { months } \\
2 \text {-year survival: } 2\end{array}$ \\
\hline 5 & Homma [14] & 2010 & 992 & Cytology & Before gastrectomy & $62(6.25)$ & \\
\hline \multirow[t]{2}{*}{6} & \multirow[t]{2}{*}{$\operatorname{Han}[5]$} & \multirow[t]{2}{*}{2011} & \multirow[t]{2}{*}{38} & \multirow[t]{2}{*}{ Cytology } & Before gastrectomy & $13(34.2)$ & \\
\hline & & & & & After gastrectomy & $15(39.5)$ & \\
\hline 7 & Fujiwara [15] & 2011 & 25 & Cytology & $\begin{array}{l}\text { CTH systemic and } \\
\text { intraperitoneal }\end{array}$ & $11(44)$ & \\
\hline 8 & Noda [16] & 2011 & 1562 & Cytology & Lack & $179(11.5)$ & \\
\hline 9 & Lee [17] & 2011 & 1072 & Cytology & After gastrectomy & $172(16)$ & \\
\hline \multirow[t]{2}{*}{10} & \multirow[t]{2}{*}{ Wong [18] } & \multirow[t]{2}{*}{2012} & \multirow[t]{2}{*}{156} & Cytology & \multirow[t]{2}{*}{ Lack } & 31 (19.9) & \\
\hline & & & & RT-PCR & & $58(37.2)$ & \\
\hline 11 & Cotte [9] & 2013 & 200 & Cytology & neo-CTH in 2 patients & $39(19.5)$ & $\begin{array}{c}\text { Presence of IFCCs in cytological } \\
\text { examination is not an independent } \\
\text { prognostic factor }\end{array}$ \\
\hline 12 & Mezhir [19] & 2013 & 22 & Cytology & Lack & $12(54.5)$ & \\
\hline \multirow[t]{2}{*}{13} & \multirow{2}{*}{$\begin{array}{l}\text { Takebayashi } \\
{[20]}\end{array}$} & \multirow[t]{2}{*}{2014} & \multirow[t]{2}{*}{102} & \multirow{2}{*}{$\begin{array}{l}\text { Cytology + } \\
\text { RT-CR + cell } \\
\text { culture }\end{array}$} & Before gastrectomy & $45(44.2)$ & \\
\hline & & & & & After gastrectomy & $80(78.4)$ & \\
\hline \multirow[t]{2}{*}{14} & \multirow{2}{*}{$\begin{array}{c}\text { Fuijwara Y } \\
\text { [21] }\end{array}$} & \multirow[t]{2}{*}{2014} & \multirow[t]{2}{*}{137} & Cytology & \multirow[t]{2}{*}{$\mathrm{aCTH}$} & $27(20)$ & \multirow{2}{*}{$\begin{array}{l}\text { Worse prognoses in patients with } \\
\text { positive RT-PCR }\end{array}$} \\
\hline & & & & RT-PCR & & $59(54)$ & \\
\hline 15 & Kano [22] & 2015 & 1039 & Cytology & Lack & $116(11)$ & $\begin{array}{l}\text { 2-year survival: } 22.9 \% \\
\text { median survival: } 11 \text { months }\end{array}$ \\
\hline 16 & Pak [23] & 2017 & 48 & Cytology & Lack & $10(21)$ & $\begin{array}{c}\text { 2-year survival: } \\
\text { positive cytology: } 25 \% \\
\text { negative cytology: } 74.5 \%\end{array}$ \\
\hline \multirow[t]{2}{*}{17} & \multirow[t]{2}{*}{$\begin{array}{c}\text { Hasbahceci } \\
{[24]}\end{array}$} & \multirow[t]{2}{*}{2018} & \multirow[t]{2}{*}{34} & \multirow[t]{2}{*}{ Cytology } & $\begin{array}{l}\text { Before } \\
\text { gastrectomy }\end{array}$ & $2(5.9)$ & \\
\hline & & & & & $\begin{array}{l}\text { After } \\
\text { gastrectomy }\end{array}$ & $1(2.9)$ & \\
\hline 18 & Ronellenfitsch & 2018 & 27 & Cytology & Gastrectomy & $2(11)$ & \\
\hline & & & & & $\begin{array}{l}\text { Gastrectomy + } \\
\text { peritoneal lavage }\end{array}$ & $8(29.6)$ & \\
\hline 19 & Virgilio [26] & 2018 & 80 & Cytology & Lack & $36(45)$ & Survival: 23 months \\
\hline
\end{tabular}

CTH - chemotherapy, neo-CTH - neoadjuvant chemotherapy, aCTH - adjuvant chemotherapy, RT-PCR - reverse transcription polymerase chain reaction

RT-PCR analysis with peritoneal lavage in addition to the pathologic $\mathrm{N}$ factor was an independent prognostic factor. There have been a number of reports of successful PCR detection in peritoneal lavage specimens in GC that showed important correlations with patient survival or peritoneal recurrence. If high-risk patients are diagnosed on the basis of the PCR test at the time of the staging laparoscopy, preoperative chemotherapy before the operation or more aggressive chemotherapy, such as intra-peritoneal chemotherapy or chemo-hyperthermia, at the time of resection may be justifiable to prevent peritoneal recurrence. Further clinical trials are needed to resolve the clinical issue [15]. Wong et al. [18] in their study also confirmed that RT-PCR assay increases the sensitivity of detection of IFCCS in the peritoneal cavity in patients with GC. In 156 patients, peritoneal lavage was performed during laparoscopy. The lavage 
Table 2. Analysis of frequency of detection of intraperitoneal free cancer cells in gastric cancer using cytology + RT-PCR, RT-PCR and cytology + RT-PCR + cell culture as a diagnostic method

\begin{tabular}{lcc}
$\begin{array}{l}\text { Method } \\
\text { Cytology + RT-PCR }\end{array}$ & First author & Proportion of positive results and confidence interval \\
& Hao [11] & $0.40(95 \% \mathrm{Cl}: 0.29-0.51)$ \\
RT-PCR & Wong [18] & $0.44(95 \% \mathrm{Cl}: 0.33-0.56)$ \\
& Fuijwara [21] & $0.37(95 \% \mathrm{Cl}: 0.30-0.45)$ \\
Cytology + RT-PCR + cell culture & Takebayashi [20] & $0.43(95 \% \mathrm{Cl}: 0.35-0.52)$ \\
\hline
\end{tabular}

$R T-P C R$ - reverse transcription polymerase chain reaction

fluid obtained was designed for cytological examination and for examination of the carcinoembryonic antigen (CEA) using RT-PCR assay. The presence of IFCCs in cytology was observed in 31 (19.9\%) patients, whereas with the use of RTPCR a positive result was obtained in 58 (37.2\%) patients. The RT-PCR examination for CEA is characterized by higher detectability of subclinical intraperitoneal dissemination, and higher sensitivity compared to the classical cytological examination. Takebayashi et al. [20] assessed the viability of IFCCS and their capability for formation of metastases in vivo. The IFCCS were obtained from peritoneal lavage in 102 patients with GC. Subsequently, cancer cells were proliferated on cell cultures. The subsequent stage of the study was injection of cancer cells into the peritoneal cavity of mice. In the study, 24 nude mice were used, which, after the injection of IFCCS, were bred for 6 weeks, and then euthanized with pentobarbital. After laparotomy, the peritoneal nodules were collected for histopathologic examination. Peritoneal nodules histologically equivalent to poorly differentiated adenocarcinoma were found in 4 mice. This study confirmed that IFCCs are capable of formation of intraperitoneal metastases.

The presence of IFCCS in cytological examination from the peritoneal cavity of patients with malignant carcinomas of the gastrointestinal tract is closely correlated with the depth of infiltration of the tumour, the degree of its differentiation, the presence of ascites, macroscopic or microscopic residual tumour, and the occurrence of distant metastases $[9,11]$. In their study, Cotte et al. [9] observed a correlation between the stage of GC and the rate of positive results of cytological tests of the peritoneal lavage fluid. The study enrolled 1,334 patients with gastrointestinal cancer, including 200 patients with GC. The material for cytological examination was obtained using peritoneal lavage with $200 \mathrm{ml}$ of saline. After waiting 2 minutes, $50 \mathrm{ml}$ of the peritoneal fluid was sucked out from the pouch of Douglas; $95.8 \%$ positive results of cytology were found in patients with cancer at the pT3/T4 stage, which suggests the exfoliation of cancer cells directly from the primary tumour. The study demonstrated that the presence of IFCCS in peritoneal lavage cytology is not an independent prognostic factor for assessment of the survival of patients and the frequency of recurrences. A positive cytology result for IFCCs does not provide new prognostic information, compared to commonly applied prognostic factors associated with the pTNM classification and the degree of differentiation of the tumour [9]. La Torre et al. [12] also emphasized that a positive result of cytological examination for IFCCS depends on the stage of the cancer. The study included 64 patients with GC. After opening the abdominal cavity, $200 \mathrm{ml}$ of saline was poured into the peritoneal cavity; the liquid was manually dispersed into the pouch of Douglas, paracolic gutters, as well as into the right and left subperitoneal area. Subsequently, $50 \mathrm{ml}$ of the lavage fluid was collected for cytological examination from various sites of the peritoneal cavity. In the study, a positive result was observed of cytology for the IFCCs in 11\% of patients; $86 \%$ of them showed stage pT3/T4, while in 100\% of patients affected lymph nodes were found. In addition, in $71 \%$ of patients the degree of differentiation of GC G3/G4 was observed. The results of this study demonstrate that in patients with a positive result of peritoneal cytology, the cancerous process is more advanced and the prognosis is poorer - opposite to the previously quoted study [9].

Radical gastrectomy with lymphadenectomy is considered the main method of treatment of GC. However, in many patients, intraperitoneal recurrence is observed after radical gastrectomy, even when the tumour had been removed with a margin free from cancer cells (resection RO). It is considered that intraperitoneal recurrence is caused by penetration of the tumour via the gastric wall, and spread of cancer cells by the lymph nodes. Nevertheless, intraperitoneal recurrence was also observed in patients with stage T1NO subjected to gastrectomy, which cannot be explained by the infiltration of cancer into the gastric wall. In addition, it was demonstrated that manipulations of the tumour during surgery increase the concentration of the mRNA carcinoembryonic antigen (CEA) in blood. This shows the possibility of the spread of cancer cells into the lymphatic vessels and stomach cavity during surgical manoeuvres, which may be the source of intraperitoneal dissemination during radical gastrectomy [5]. The vast majority of free cancer cells are subject to apoptosis in the peritoneal cavity - these cells are exposed to mechanical damage or the action of the immune system. However, surgical injury results in the violation of tissue integrity, induces an inflammatory state, and increases the production of proteins promoting angiogenesis. Additionally, there occurs suppression of the immune system and increased adhesion of cancer cells to the peritoneal cavity. Hence, despite the fact that gastrectomy decreases tumour mass, somehow, it facilitates intraperitoneal dissemination [20]. In the study by Han et al. [5], an increase was found in the frequency of detection of IFCCS 


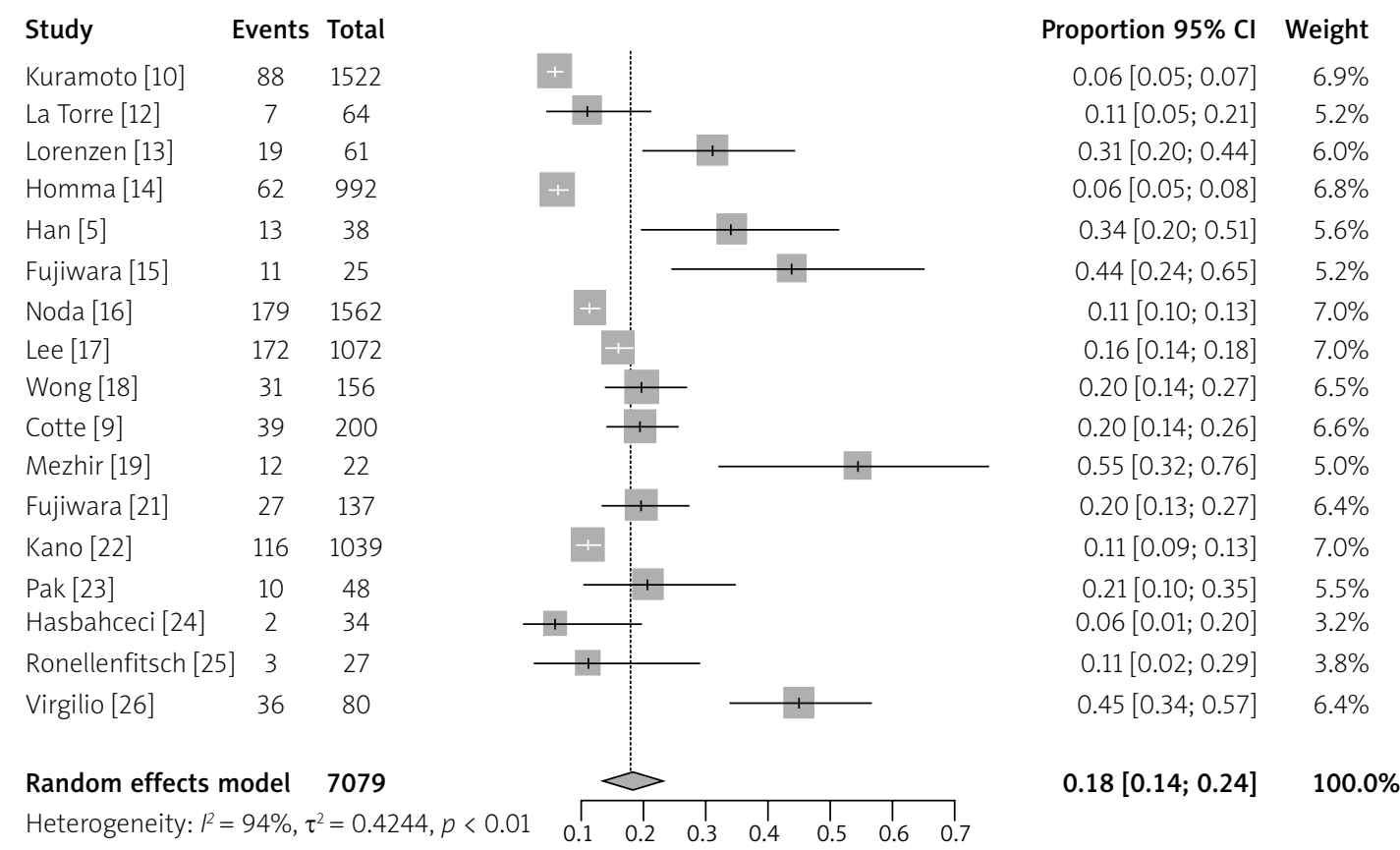

Fig. 2. Meta-analysis of the frequency of detection of IFCCS in gastric cancer using cytology as a diagnostic method

in patients after gastrectomy with D2 lymphadenectomy. Thirty-eight patients with GC were enrolled in the study. In each of them, gastric cavity lavage was applied via the nasogastric tube using $200 \mathrm{ml}$ of saline before gastrectomy when the duodenum was closed by means of an intestinal clip. Subsequently, the peritoneal cavity was washed using $500 \mathrm{ml}$ of saline prior to and after gastrectomy. After the procedure, the resected stomach was placed in a container with $500 \mathrm{ml}$ of saline, where it was washed for 15 seconds. The lavage fluid was designed for cytological examination. During the surgical procedure, blood and lymphatic vessels were closed by means of clips, bipolar electrodes, or harmonic scalpels. Samples of the lavage fluid were examined using a classical cytological test and RT-PCR. Free cancer cells in the washing from peritoneal lavage prior to gastrectomy were detected in $34.2 \%$ of cases, whereas after gastrectomy, this percentage was $39.5 \%$ of cases. The researchers emphasized that free cancer cells may be released from the gastric lumen and from open lymphatic vessels while manipulating the tumour. Therefore, every effort should be made during the surgical procedure not to allow their leakage into the peritoneal cavity. In the study by Takebayashi [20], peritoneal lavage was applied before and after gastrectomy with lymphadenectomy in 102 patients with GC. The material for the study was obtained by washing the peritoneal cavity with $100 \mathrm{ml}$ of saline prior to and after gastrectomy; $50 \mathrm{ml}$ of the lavage fluid was intended for cytology, while the remaining $50 \mathrm{ml}$ was for the extraction of cDNA and cell culture. Before gastrectomy, IFCCS were found in $44.2 \%$ of patients, while directly after gastrectomy they were found in $78.4 \%$. Hasbahceci et al. [24], in their study of 2018, also examined the peritoneal lavage fluid in patients before and after gastrectomy. After intraoperative examination of the peritoneal cavity, which did not show the presence of metastases in the perito- neum, the peritoneal cavity was washed with $200 \mathrm{ml}$ of saline. A minimum of $1 / 3$ was aspirated from several sites in the peritoneum - from the site of primary tumour, left and right subperitoneal space and the pouch of Douglas. After performance of gastrectomy, the peritoneal cavity was washed again in the above-described way. Patients with massive intraperitoneal dissemination and patients with surgically inoperable tumours were excluded from the study. The limitation of this study was the inclusion of patients after neoadjuvant chemotherapy and the use of exclusively cytological examination, without application of additional techniques of molecular biology. The results of cytological examination of the lavage fluid from the peritoneal cavity were unsatisfactory. Only 2 positive cytology results were found prior to gastrectomy per 34 examined patients (5.9\%). Cytological examination from peritoneal lavage after gastrectomy showed only one positive result (2.9\%). The researchers suggested that the use of neoadjuvant chemotherapy may exert an effect on the result of peritoneal lavage cytology.

Material for cytological examination for IFCCS is usually collected during laparotomy or laparoscopy. Pak et al. [23] developed a method of percutaneous peritoneal lavage as the method minimally invasive for a patient. The main aim of the study was to determine the sensitivity and specificity of percutaneous peritoneal lavage and its safety for the patient. The study comprised 48 patients with GC. In each patient, percutaneous peritoneal lavage was performed via the Veress needle $800 \mathrm{ml}$ of warm saline was administered, and subsequently, a minimum of $5 \mathrm{ml}$ of peritoneal fluid was sucked out for cytological examination. After percutaneous peritoneal lavage, laparoscopic peritoneal lavage was performed, and a minimum of $5 \mathrm{ml}$ of peritoneal fluid was taken for cytological examination. In 10 (20.8\%) patients, a positive cytology result was observed from per- 
cutaneous peritoneal lavage. In all 10 patients, a positive result of cytology of the laparoscopic peritoneal lavage was also found. In 2 patients with a negative result of cytological examination from the fluid obtained by the percutaneous method, the presence of IFCCS was confirmed in cytology obtained by the laparoscopic method. A 95.8\% correlation was found between cytological examination of the peritoneal fluid obtained by the percutaneous method and laparoscopic method; 2-year survival of patients with positive cytology was $25 \%$, whereas in those with negative cytology it was $74.5 \%$. Summing up, percutaneous peritoneal lavage is characterized by high sensitivity and specificity, compared to laparoscopic lavage - the present standard of collection of fluid for cytological examination for IFCCS. This method may be an effective instrument for quick diagnosis of IFCCs in GC.

The first laparoscopic gastrectomy performed due to malignant GC was performed in 1993. Since then, many scientific publications have appeared which emphasize the advantages of laparoscopic gastrectomy: low postoperative morbidity and mortality, higher quality of life after surgery, and a higher long-term survival rate compared to gastrectomy by the open method. Nevertheless, the use of laparoscopic surgery in advanced GC is not commonly accepted. The main concerns related to laparoscopic resections of the stomach due to malignant cancer pertain to the preservation of the margin free from cancer cells, radical character of lymphadenectomy, and whether laparoscopic gastrectomy is conducive to the exfoliation of free cancer cells from the surface of the tumour. For this reason, in 2010, Hao et al. [7] conducted a study comparing the frequency of occurrence of IFCCs after gastrectomy performed using the laparoscopic technique and an open technique. The study covered 164 patients with GC -83 patients had undergone surgery using the laparoscopic technique, and 81 by the open technique. The selection of the surgical method depended on the patient's decision. None of the patients received neoadjuvant chemotherapy. The material for the study was collected by washing the peritoneal cavity with $100 \mathrm{ml}$ of saline at the beginning of the surgery. Subsequently, the lavage fluid was collected for examination after gentle stirring of the gastric content. The subsequent sample was taken before closing the stomach after peritoneal lavage with $500-1000 \mathrm{ml}$ of saline; $50 \mathrm{ml}$ of the sample was intended for cytological examination, while the remaining $50 \mathrm{ml}$ was for RT-PCR. The post-operative IFCCS rate in cytology was $27.7 \%$ using gastrectomy by the laparoscopic method, and $29.63 \%$ using the open technique. In the RT-PCR assay, the presence of the IFCCS was observed in $32.53 \%$ of cases after laparoscopic gastrectomy, and in $35.80 \%$ of cases after open gastrectomy. In general, using RT-PCR and cytology, IFCCS were found in $39.76 \%$ and $43.20 \%$ of cases after laparoscopic gastrectomy and open gastrectomy, respectively. Intraperitoneal metastasis was observed in $18 \%$ of patients after laparoscopic gastrectomy, and in $19.75 \%$ of patients after gastrectomy by the open method. The median survival of patients with IFCCs was 20 months, while the median survival of patients with a negative result of examination for IFCCs was 31 months. The survival curve of patients af- ter laparoscopic gastrectomy was similar to that after gastrectomy by the open method. Summing up, laparoscopic techniques applied in patients operated on due to GC do not cause an increased risk for the dissemination of free cancer cells in the peritoneal cavity, compared to the open method. In order to decrease the risk of dissemination of cancer cells during the surgical procedure, it is recommended to observe the principles of oncologic surgery, e.g. a radical resection of the tumour with a minimum margin of $5 \mathrm{~cm}$, and protection of the site of incision of abdominal integuments against contamination by the preparation.

In the study by Ronellenfitsch [25] of 2018, conducted among patients after gastrectomy with D2 lymphadenectomy, extensive washing of the peritoneal cavity was applied in order to eliminate free cancer cells. The study was discontinued considering the fact that after the surgical procedure free cancer cells were observed in only $11.1 \%$ of cases. In none of these cases did extensive peritoneal washing eliminate the presence of free cancer cells, while after washing the presence of free cancer cells was observed in $29.6 \%$ of cases. This study suggests that extensive washing of the peritoneal cavity results in dissemination of the free cancer cells in the peritoneal cavity; therefore, this management may be potentially harmful.

In turn, a study by Kuramoto [10] published in 2009 demonstrated that peritoneal lavage and the use of intraperitoneal chemotherapy prolongs the 5-year survival of patients with GC. The study included 88 patients with GC who had a positive cytology result for the presence of IFCCS. The patients were randomly assigned to 3 groups in which the following were applied: surgical treatment, surgical treatment with intraperitoneal chemotherapy, and surgical treatment with intraperitoneal chemotherapy and peritoneal lavage. The 5-year survival of patients who had undergone surgical treatment with intraperitoneal chemotherapy and peritoneal lavage was $43.8 \%$, whereas 5 -year survival of those who had undergone surgical treatment as the only method was $4.6 \%$. Also, in this group of patients, intraperitoneal recurrence was more rarely observed. Considering the above, the authors of the report recommend the use of intraperitoneal chemotherapy and peritoneal lavage as a standard prophylaxis of intraperitoneal dissemination in patients subjected to resection of the stomach due to cancer.

The prognosis in patients with the diagnosis of intraperitoneal dissemination in GC is very unfavourable [18]. It is necessary to establish new strategies for the treatment of patients with advanced GC. One of them is prevention of the spread of cancer cells from the lymphatic vessels by using surgical instruments for closing vessels. Compared to coagulation, the instruments for closing vessels decrease the leakage of lymph from the lymphatic vessels. However, in a study by Takebayashi et al. [20], despite the use of these instruments, the spread of free cancer cells in the peritoneal cavity was still observed after the procedures of resection of the stomach with lymphadenectomy. This indicates insufficient effectiveness of instruments for closing vessels currently available on the market. It is necessary to improve them from the aspect of prevention of intraperitoneal dissemination during surgical proce- 
dures. One of the strategies is the elimination of cancer cells which have already spread in the peritoneal cavity. The presence of the blood-peritoneal barrier is the cause of a poor effect of intravenous chemotherapy in the case of intraperitoneal metastases. The use of hyperthermic intraperitoneal chemoperfusion (HIPEC) allows one to obtain a high concentration of the chemotherapeutic agent in the peritoneal cavity, with a simultaneous low concentration in blood. Moreover, the drug administered into the peritoneal cavity is absorbed and transported via the portal vein to the liver acting on micrometastases which are formed there. Hyperthermia alone causes direct damage to the IFCCS, and apart from this, acts synergistically with the chemotherapeutic drug - increases its cytotoxicity and the depth of penetration into the metastatic node [7]. In intraperitoneal dissemination in GC, the combination of complete cytoreductive surgery with HIPEC is the only method of treatment which allows long-term survival to be achieved. Many scientific studies confirm that the use of HIPEC after cytoreductive surgery as prophylaxis for intraperitoneal dissemination increases 5-year survival and median survival of patients [2].

\section{Conclusions}

At present, the diagnosis of the presence of IFCCs in the peritoneal cavity is treated equally to the $M$ category according to the 8th edition of the TNM classification by the AJCC. The effectiveness of detection of IFCCS is still imperfect and requires further studies in order to optimize the assessment of the stage of GC. In the case of detection of the presence of IFCCS in patients with GC, the patient should be qualified for chemotherapy, or possibly the use of HIPEC should be considered.

\section{Acknowledgments}

Project financed under the program of the Minister of Science and Higher Education called „Regional Initiative of Excellence" in the years, project no 024/RID/2018/19, amount of financing 11,999,000.00 zł.

The authors declare no conflict of interest.

\section{References}

1. Sitarz R, Skierucha M, Mielko J, Offerhaus GJA, Maciejewski R, Polkowski WP. Gastric cancer: epidemiology, prevention, classification, and treatment. Cancer Manag Res 2018; 10: 239-248.

2. Glehen O, Passot G, Villeneuve L, Vaudoyer D, Bin-Dorel S, Boschetti G, Piaton E, Garofalo A. GASTRICHIP: D2 resection and hyperthermic intraperitoneal chemotherapy in locally advanced gastric carcinoma: a randomized and multicenter phase III study. BMC Cancer 2014; 14: 183.

3. Głuszek S, Kot M, Kuchinka J, Matykiewicz J. The influence of splenectomy performed simultaneously with gastrectomy on postoperative complications in patients with gastric cancer un dergoing surgery with the intention to treat. Pol Przegl Chir 2014; 86: 312-318.

4. Sun F, Feng M, Guan W. Mechanisms of peritoneal dissemination in gastric cancer. Oncol Lett 2017; 14: 6991-6998.
5. Han TS, Kong SH, Lee HJ, Ahn HS, Hur K, Ju J, Kim WH, Yang HK. Dissemination of Free Cancer Cells from the Gastric Lumen and from Perigastric Lymphovascular Pedicles during Radical Gastric Cancer Surgery. Ann Surg Oncol 2011; 18: 2818-2825.

6. Brierley JD, Gospodarowicz MK, Wittekind C. TNM classification of malignant tumors. Via Medica 2017: 69-72.

7. Ji ZH, Peng KW, Li Y. Intraperitoneal free cancer cells in gastric cancer: pathology of peritoneal carcinomatosis and rationale for intraperitoneal chemotherapy/hyperthermic intraperitoneal chemotherapy in gastric cancer. Transl Gastroenterol Hepatol 2016; 1: 69 .

8. Hasbahceci M, Akcakaya A, Guler B, Kunduz E, Malya FU, Muslumanoglu M. Use of peritoneal washing cytology for the detection of free peritoneal cancer cells before and after surgical treatment of gastric adenocarcinoma. J Cancer Res Ther 2018; 14: 1225-1229.

9. Cotte E, Peyrat P, Piaton E, et al. Lack of prognostic significance of conventional peritoneal cytology in colorectal and gastric cancers: Results of EVOCAPE 2 multicentre prospective study. Eur J Surg Oncol 2013; 39: 707-714.

10. Kuramoto M, Shimada S, Ikeshima S, Matsuo A, Yagi Y, Matsuda M, Yonemura Y, Baba $\mathrm{H}$. Extensive intraoperative peritoneal lavage as a standard prophylactic strategy for peritoneal recurrence in patients with gastric carcinoma. Ann Surg 2009; 250: 242-246.

11. Hao YX, Zhong H, Yu PW, Qian F, Zhao YL, Shi Y, Tang B. Influence of laparoscopic gastrectomy on the detection rate of free gastric cancer cells in the peritoneal cavity. Ann Surg Oncol 2010; 17: 65-72.

12. La Torre M, Ferri M, Giovagnoli MR, Sforza N, Cosenza G, Giarnieri E, Ziparo V. Peritoneal wash cytology in gastric carcinoma. Prognostic significance and therapeutic consequences. Eur J Surg Oncol 2010; 36: 982-986.

13. Lorenzen S, Panzram B, Rosenberg R, et al. Prognostic significance of free peritoneal tumor cells in the peritoneal cavity before and after neoadjuvant chemotherapy in patients with gastric carcinoma undergoing potentially curative resection. Ann Surg Oncol 2010; 17: 2733-2739.

14. Homma Y, Ushida S, Yamada M, Kobayashi H, Suzuki K. Positive peritoneal washing cytology in multiple cavities can predict poor prognosis of advanced gastric cancer patients. Ann Surg Oncol 2010; 17: 455-460.

15. Fujiwara $\mathrm{Y}$, Okada K, Hanada $\mathrm{H}$, et al. The clinical importance of a transcription reverse-transcription concerted (TRC) diagnosis using peritoneal lavage fluids in gastric cancer with clinical serosal invasion: a prospective, multicenter study. Surgery 2014; 155: 417-423.

16. Noda S, Yashiro M, Toyokawa T, Morimoto J, Shinto O, Muguruma K, Sawada T, Hirakawa K. Borrmann's Macroscopic Criteria and p-Smad2 Expression Are Useful Predictive Prognostic Markers for Cytology-Positive Gastric Cancer Patients Without Overt Peritoneal Metastasis. Ann Surg Oncol 2011; 18: 3718-3725.

17. Lee SD, Ryu KW, Eom BW, Lee JH, Kook MC, Kim YW. Prognostic significance of peritoneal washing cytology in patients with gastric cancer. Br J Surgery 2011; 99: 397-403.

18. Wong J, Kelly KJ, Mittra A, Gonen M, Allen P, Fong Y, Coit D. Rt-PCR increases detection of submicroscopic peritoneal metastases in gastric cancer and has prognostic significance. J Gastrointest Surg 2012; 16: 889-896.

19. Mezhir JJ, Posner MC, Roggin KK. Prospective clinical trial of diagnostic peritoneal lavage to detect positive peritoneal cytology in patients with gastric cancer. J Surg Oncol 2013; 107: 794-798.

20. Takebayashi K, Murata S, Yamamoto H, et al. Surgery-Induced Peritoneal Cancer Cells in Patients Who Have Undergone Curative Gastrectomy for Gastric Cancer Ann Surg Oncol 2014; 21: 19911997.

21. Fujiwara Y, Takiguchi S, Nakajima K, et al. Neoadjuvant intraperitoneal and systemic chemotherapy for gastric cancer patients with peritoneal dissemination. Ann Surg Oncol 2011; 18: 3726-3731.

22. Kano Y, Kosugi S, Ishikawa T, et al. Prognostic significance of peritoneal lavage cytology at three cavities in patients with gastric cancer. Surgery 2015; 158: 1581-1589. 
23. Pak LM, Coit DG, Eaton AA, et al. Percutaneous Peritoneal Lavage for the Rapid Staging of Gastric and Pancreatic Cancer. Ann Surg Oncol 2017; 24: 1174-1179.

24. Hasbahceci M, Akcakaya A, Guler B, Kunduz E, Malya FU, Mus lumanoglu M. Use of peritoneal washing cytology for the de tection of free peritoneal cancer cells before and after surgical treatment of gastric adenocarcinoma. J Can Res Ther 2018; 14 1225-1229.

25. Ronellenfitsch U, Ernst K, Mertens C, et al. Extensive intraperitoneal lavage to eliminate intraperitoneal tumor cells in gastrectomy with D2 lymphadenectomy for gastric cancer. Tumori 2018; 104 361-368.

26. Virgilio E, Giarnieri E, Giovagnoli MR, et al. Presence of cancer cells in gastric lavage of gastric cancer patients as an indicator of ad vanced disease, predictor of tumour aggressive phenotype and independent prognostic factor for poor survival: The endolumina metastatic pathway of gastric cancer and GLO/GL1 classification. Cytopathology 2018; 29: 41-48.

27. Ito S, Kodera Y, Mochizuki Y, Kojima T, Nakanishi H, Yamamura Y. Phase II clinical trial of postoperative S-1 monotherapy for gastric cancer patients with free intraperitoneal cancer cells detected by real-time RT-PCR. World J Surg 2010; 34: 2083-2089.

\section{Address for correspondence}

\section{Magdalena M. Kołomańska}

Department of Surgery and Surgical Nursing

with Laboratory of Genetics and Scientific Research Collegium Medicum

Jan Kochanowski University

19a IX Wieków Kielc Ave.

25-317 Kielce, Poland

e-mail: mkolomanska92@gmail.com

Submitted: 22.10 .2019

Accepted: 9.02 .2020 